WSRC-MS $-90-323$

DE92 009809

\title{
TRITIUM ATMOSPHERIC TRANSPORT AND DEPOSITION FOLLOWING ACUTE RELEASES - COMPARISONS WITH SIMPLE TRANSPORT MODELS (U)
}

by

C. E. Murphy, Jr., L. R. Bauer, and D. Hoel

Westinghouse Savannah River Company

Savannah River Laboratory

Aiken, South Carolina 29808

A paper proposed for presentation at the

4th Topical Meeting on Tritium Technology in Fission, Fusion, and

Isotopic Applications

Albv juerque, New Mexico

September 29 - Dctober 4, 1991

and for publication in the proceedings

This paper was prepared in connection with work done under Contract No. DE-AC09-89SR18035 with the U.S. Department of Energy. By acceptance of this paper, the publisher and/or recipient: acknowledges the U.S. Government's right to retain a nonexclusive, royalty-free license in and to any copyright covering this paper, along with the right to reproduce and to authorize others to reproduce ail or part of the copyrighted paper.

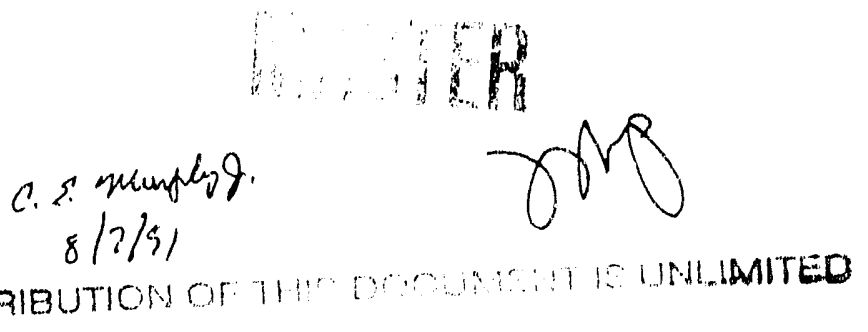




\section{DISCLAIMER}

This report was prepared as an account of work sponsored by an agency of the United States Government. Neither the United States Government nor any agency thereof, nor any of their employees, makes any warranty, express or implied, or assumes any legal liability or responsibility for the accuracy, completeness, or usefulness of any information, apparatus, product, or process disclosed, or represents that its use would not infringe privately owned rights. Reference herein to any specific commercial product, process, or service by trade name, trademark, manufacturer, or otherwise does not necessarily constitute or imply its endorsement, recommendation, or favoring by the United States Government or any agency thereof. The views and opinions of authors expressed herein do not necessarily state or reflect those of the United States Government or any agency thereof. 


\title{
TRITIUM ATMOSPHERIC TRANSPORT AND DEPOSITION FOLLOWING ACUTE RE- LEASES - COMPARISONS WITH A SIMPLE TRANSPORT MODEL
}

\author{
by C.E. Murphy Jr., L.R. Bauer, and D.D. Hoel \\ Westinghouse Savannah River Company \\ Aiken, SC
}

\section{ABSTRACT}

During 35 years of operation of the Savannah River Site (SRS) there have been a small number of inadvertent tritium releases to the atmosphere. After detection of the releases by stack monitors, field crews were dispatched to determine the concentration of tritium in the environment. The objective of the measurements was to verify environmental concentrations calculated by dose assessment models.

Air samplers were used to verify the concentration levels and tritium forms during the plume passage. It was not feasible to take enough samples in the plume path to determine the two dimensional distribution of tritium concentration in the plume. However, the ground level distribution was very well reflected in vegetation samples. Therefore, it is usually possible to determine plume shape, plume width, and the relative maximum concentration as the plume moves downwind from the vegetation samples. In eight of the nine releases studied, the monitoring data allowed comparison with atmospheric transport models.

\section{INTRODUCTION}

The SRS is a major producer of tritium for National Defense. Tritium is produced by nuclear reaction in heavy water reactors. In addition to the reactors, the site includes fuel fabrication, target and fuel reprocessing, storage and research facilities. In the past, SRS also operated a heavy water production facility. There have been low-level, chronic tritium releases from all of these facilities. All of the major acute, atmospheric tritium releases have come from the tritium separations facility where tritium is separated from the reactor targets, purified, and stored.

None of the releases caused a significant ciose to the public. The largest, potential, individual off-site dose from any of the releases was calculated to be $1.6 \mathrm{mrem}$. The population dose from this same release was 46 person-rem which represents $0.084 \%$ of the natural background radiation dose to the population in the path of the release. However, the releases have provided an opportunity to study the transport, deposition, and cycling of tritium in the environment.

\section{POST-RELEÁSE MEASUREMENTS}

The available technology and methodology for making measurements after detection of a tritium release have evolved over the period from the first acute release in 1974 until the present. However, the chronalogy of events has remained the same. Initial measurements we made in the 60meter stack where all of the releases entered the environment. After the release has been verified, sampling crews are sent to the field. Field measurement methodolgy was originally based on experience gained from measurement of chronic releases. Typically samples are taken of vegetation, air, surface water, and milk. 
Stack Measurements

The tritium concentration of a flowing sample of stack gas is measured with a Kanne ionization chamber. The amount of tritium in the release is calculated by multiplying the air flow in the stack by the integral, average tritium concentration during the time interval of the release.

In recent years the stack sampling system has been modified to allow measurement of the chemical form of tritium in a release. Two Kanne chambers are used. In one chamber the moisture is removed from the air before measurement. In the other chamber the air is not dried. The amount of tritiated water in the release is measured by subtracting the tritium remaining in the dried air from the total tritium measured by the Kanne chamber receiving undried ai-. Under SRS conditions most of the tritium measured in the chamber receiving dry air is in the form of hydrogen.

\section{Field Air Samples}

The portable, field tritium air sampler used at SRS uses molecular sieve to remove a sample of air moisture followed by a second sieve trap where tritiated hydrogen is oxidized and collected by palladium coated sieve. Air flow rates and sampling periods are carefully set before placement in the field. The water from the sieve is collected after exposure by heating under vacuum. The tritium is counted by proportional counting after dissociation of the water to hydrogen.

One of the initial uses of this sampler was during the May 1974 release when a sampling crew was able to catch up with the plume and measure the concentration of water vapor and hydrogen in the release. SRS continues to rely on this technique and the number of samplers available for deployment has increased to the eighteen that were used in the July, 1987 release.
Vegetation Samples

Vegetation samples are cut and stored in plastic bags. The samples are processed as soon as practical after collection. The samples are vacuum distilled to remove an aliquot of water. The water is then counted by liquid scintillation.

Vegetation sampleing does not require special field equipment and can be done quickly by field crews. Samples often number in the hundreds and transects across a plume path can have fifty samples. Vegetation sampling has proved to be very effective in post-release evaluation of the plume path. On the other hand, the results are not available quickly enough to be of value in emergencies.

\section{Other Samples}

Milk samples are vacuum distilled and the water is counted by liquid scintillation. Milk samples are made only in those cases when the release of the plume passes over a farm where cows are present. Surface water samples are directly counted by liquid scintillation unless they are discolored, in which case they are vacuum distilled.

\section{RESULTS}

As suggested above, though the results of air measurements are extremely valuable for verification of the air concentration and the chemical form of the release, there are too few samples to allow complete characterization of the plume. However it is possible to estimate many plume characteristics from the vegetation samples. Fig. 1 shows the path of the nine releases which are the subject of this paper. The trajectories were initially estimated on the basis of meteorological data, but were later confirmed by the path observed from the vegetation. 


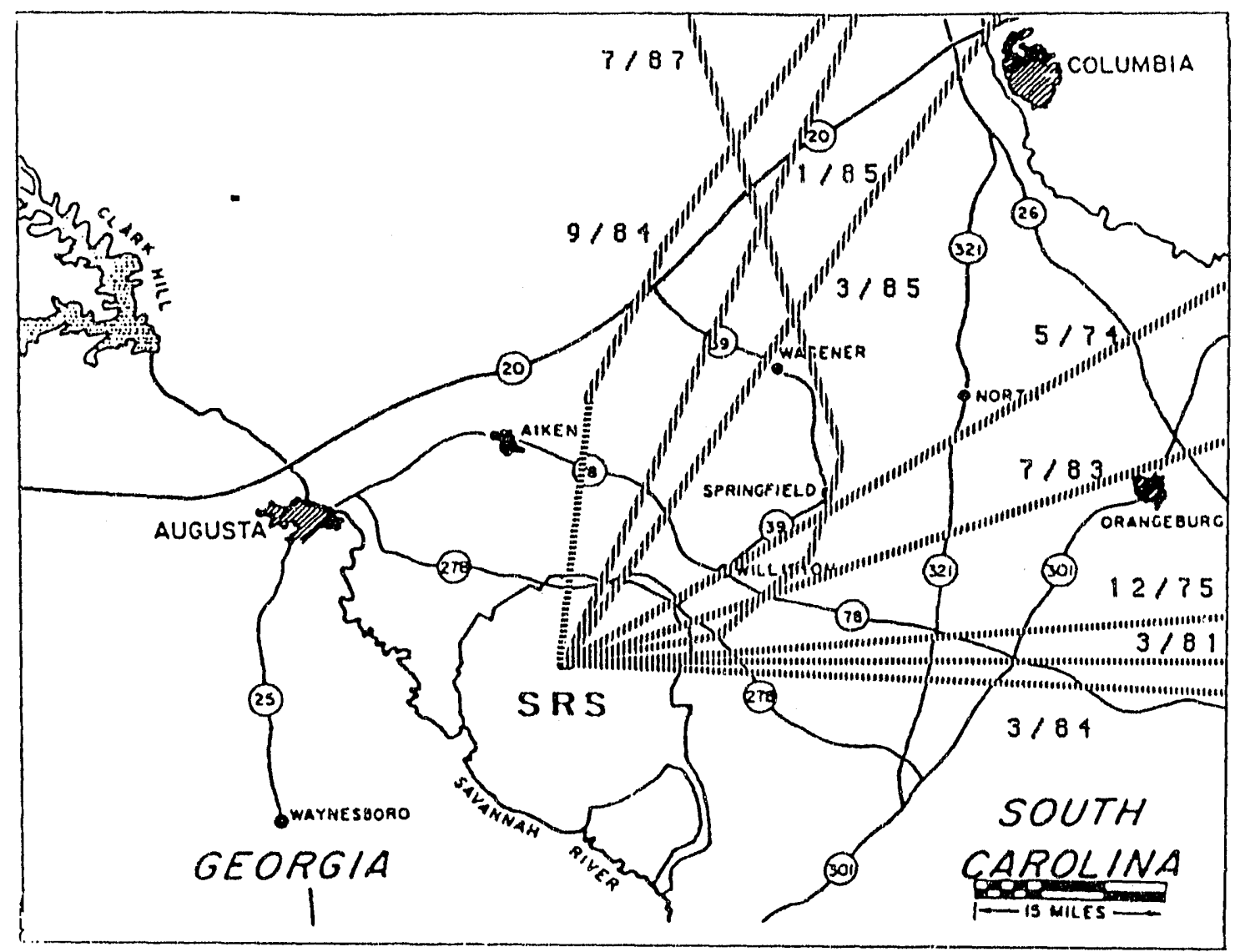

Fig. 1 Release paths determined from tritiated water analysis of vegetation collected on the basis of meteorological forecasts.

It is evident that most of the releases had a trajectory toward the northeast quadrant of the map. This is probably due to chance. The wind blows from all direction during the year, with only a small preference toward the north and east.

Fig. 2 illustrates the type of data that are provided by the vegetation analysis. The concentrations and distances along the map grid are logarithmically transformed so that all the data from the release can be displayed in one figure. This approach obscures the fact that the concentrations are much higher near the release point. (The release point is indicated by the pillar in the lowest part of the graph). The distance across the release path is also compressed in the cross-sections furthest from the release point.
Even with the distortions of the logarithmic axes it is possible to see some of the uses and limitations of these data. The general guassian form of the plume can be seen in four of the cross-sections. The number of samples is great enough to determine the relative peaks between the cross-sections, and the width is sufficiently well-defined to estimate the cross-path standard deviation.

It is also evident that the cross-sections are not perpendicular to the plume path and must be adjusted before calculation of the plume width standard deviation. In the third path it is obvious that the path is not only not perpendicular to the plume path but curved. The fourth path away from the source does not extend far enough to cover the 


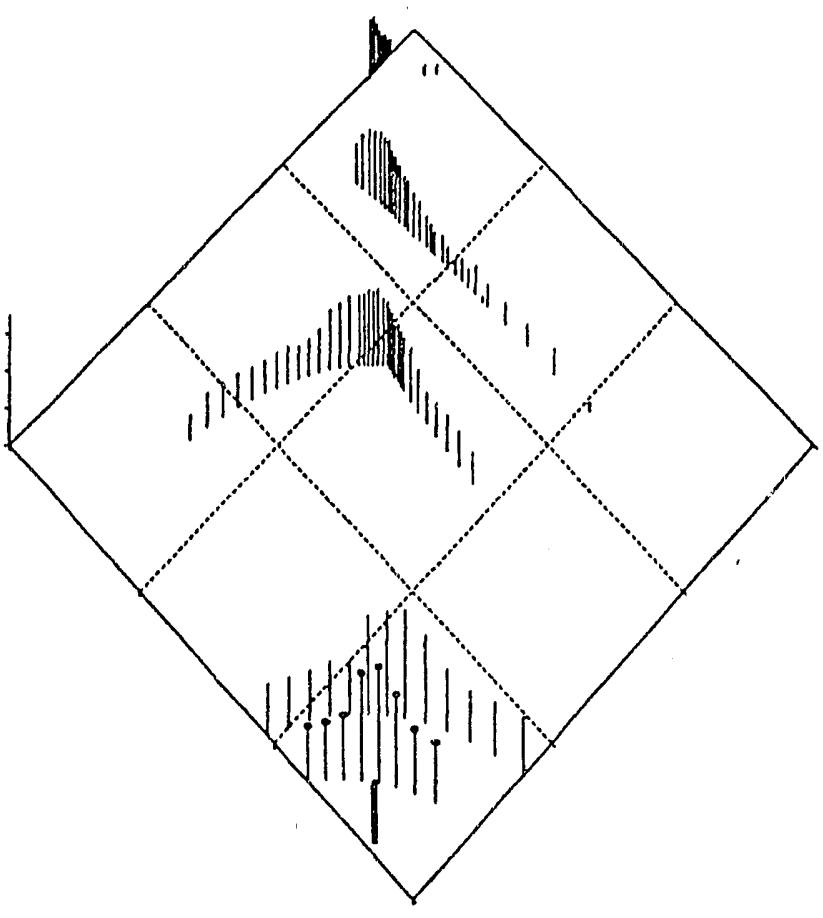

Fig. 2 Vegetation tritiated water contents down wind of the source of an atmospheric release. All coordinates are logarithmic scale to allow display on the same plot. plume at one end and the coverage in the fifth path is not sufficient to determine either the maximum concentration or the width. Most of the results of the vegetation samples have these sorts of problems but still contain enough information to be of value.

Table 1 summarizes the maximum values of the vegetation water at four distances from the source and the maximum surface water and milk values for the nine releases with the most complete data. Inspection of the data suggests some characteristics of the releases. The peak concentration of tritiated water in the leaves usually decreases with distance from the SRS, with the lowest values generally at the furthest distance. However the maximum on-site concentration may be lower than the concentration at some point further downwind. The likely cause is that the plume has not reached the ground inside the SRS boundary under the meteorological conditions present during some of the releases. This type of behavior can be predicted by simple meteorological models.

Table1. Maximum Environmental Concentrations Following Tritium Releases, $\mathrm{pCi} / \mathrm{ml}$.

\begin{tabular}{|c|c|c|c|c|}
\hline \multirow[b]{2}{*}{ Date } & \multicolumn{4}{|c|}{ Vegetation } \\
\hline & On Site & Perimeter & $-40 \mathrm{~km}$ & $\approx 80 \mathrm{kr}$ \\
\hline $5 / 2 / 74$ & 25 & 4630 & 310 & \\
\hline $12 / 31 / 75$ & 687 & 92 & 8 & \\
\hline $3 / 27 / 81$ & 4860 & 270 & ND & \\
\hline $7 / 16 / 83$ & 150 & 110 & 80 & \\
\hline $3 / 23 / 84$ & 89 & 500 & 1380 & \\
\hline $9 / 2 / 84$ & 500 & 2500 & 9900 & \\
\hline $1 / 31 / 85$ & 7600 & 450 & 380 & \\
\hline $3 / 27 / 85$ & 61800 & 970 & 590 & \\
\hline $7 / 31 / 87$ & 5760 & 4690 & 34 & \\
\hline
\end{tabular}

\begin{tabular}{rrc}
\hline & \multicolumn{2}{c}{ Maximum } \\
Surface & & \\
Water & Milk & Reference \\
\hline 138 & 375 & 1 \\
3 & 9 & 2 \\
9 & 1 & 3 \\
23 & 4 & 4 \\
120 & 69 & 5 \\
ND & 47 & 6 \\
140 & 2 & 7 \\
384 & 6 & 7 \\
47 & 4 & 8
\end{tabular}

ND Data not taken. 
Comparison to a Simple Model

It is reasonable to assume that the concentration of tritiated water in vegetation will be proportional to the exposure to the tritiated water vapor in the atmosphere above the vegetation. Centerline exposure $\left(\Psi_{m \times}\right)$ the average concentration in the air at the center of the plume multiplied by the time of contact with that air, can be calculated at the surface at any distance from the source using the model described by Slade?

$$
\Psi_{m x}=Q /\left(\pi \sigma_{y I} \sigma_{z l} u\right) \exp \left[-h^{2} /\left(2 \sigma_{z I}\right)\right]
$$

The paraneters arc total release $(Q)$ wind speed, $u$, the cross-wind standard deviation $\left(\sigma_{\mathrm{yl}}\right)$ the vertical standard deviation $\left(\sigma_{z 1}\right)$ and the height of the release $(h)$. Table 2 summarizes the conditions immediately after each of the atmospheric tritium releases. The releases took place under a wide range of meteorological conditions, during different seasons of the year and beginning at different times of the day.

Fig. 3 shows the results of calculations of the maximum centerline exposure compared to the maximium concentration measured in the veg-

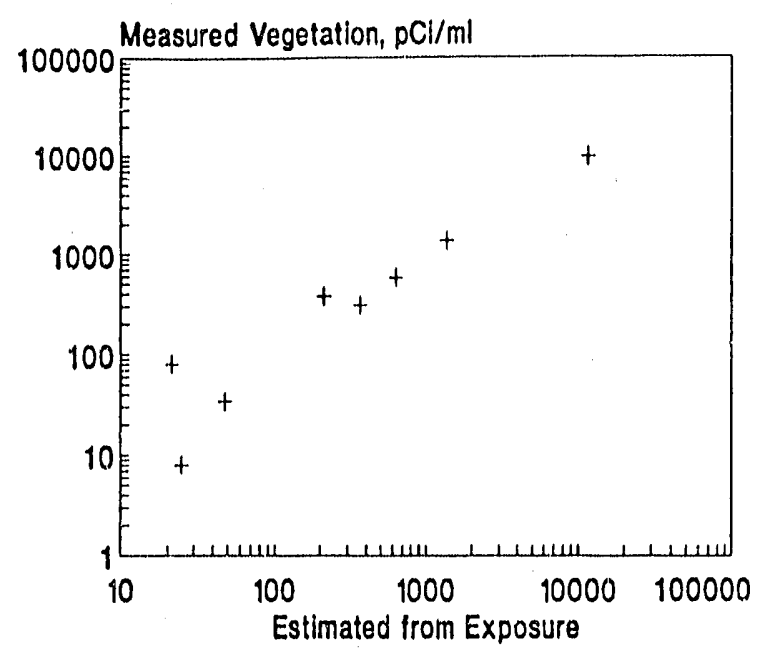

Fig. 3 The maximum tritiated water content of vegetation leaves collected at approximately $40 \mathrm{~km}$ from the source of the release compared to estimates calculated from exposure to tritiated water vapor for each release.

Table 2. Tritium Release Characteristics.

\begin{tabular}{lrrrrrl} 
Date & Time & $\begin{array}{c}\text { Release, } \\
\text { Curies }\end{array}$ & \%HTO & $\begin{array}{l}\text { HTO } \\
\text { Curies }\end{array}$ & $\begin{array}{l}\text { Wind } \\
\text { Speed.m/s }\end{array}$ & $\begin{array}{l}\text { Atmospheric } \\
\text { Stability Class }\end{array}$ \\
\hline $5 / 2 / 74$ & 755 & 479000 & 1.0 & 4790 & 3 & Neutral \\
$12 / 31 / 75$ & 2000 & 182000 & 0.6 & 1092 & 10 & Neutral \\
$3 / 27 / 81$ & 845 & 32934 & 100.0 & 32934 & 7 & Unstable \\
$7 / 16 / 83$ & 2013 & 56000 & 1.0 & 560 & 6 & Neutral \\
$3 / 23 / 84$ & 440 & 7500 & 70.0 & 5250 & 5 & Stable \\
$9 / 7 / 84$ & 1900 & 43800 & 100.0 & 43800 & 5 & Stable \\
$1 / 31 / 85$ & 1400 & 9300 & 50.0 & 4650 & 5 & Neutral \\
$3 / 27 / 85$ & 1353 & 19422 & 99.9 & 19403 & 7 & Neutral \\
$7 / 31 / 87$ & 855 & 172000 & 2.7 & 4644 & 2 & Unstable
\end{tabular}


etation at approximately $40 \mathrm{~km}$ from the release source.

Calculations have also been made at the SRS boundary and the $80 \mathrm{~km}$ distance. The results of comparisons are not as good. At the SRS boundary the problem appears to be predicting when the plume will reach the surface. That is, the calculation of the standard deviation of the vertical spread $\left(\sigma_{z}{ }^{\prime} s\right)$. At the greater distance, problems arise both because the data are not as complete and may miss the actual maximum and, in some cases, the plume no longer appears to be Gaussian in form.

\section{CONCLUSIONS}

It appears that the tritiated water content of vegetation is approximately proportional to the exposure to tritiated water vapor in the atmosphere above a particular location. This means that the concentration pattern in vegetation can be used to determine the path and horizontal spread of a release of tritiated water.

It is also possible to use these data to test atmospheric dispersion models. A test of a simple gaussian model suggests that this model is appropriate for estimating concentrations in the air at intermediate distances (at least 20-60 km) from the source. Closer to the source there appear to be some problems in estimating the vertical dispersion.

It should be noted that this technique should also work for releases of tritiated hydrogen. Although, in this case the tritium is absorbed by the soil and then transported from the soil to the vegetation. It is possible that a time lag as great as a few days may be introduced if large trees are used in sampling.

\section{REFERENCES}

1. Marter, W.L. 1975. Analysis of Effects of a Tritium Release from the Savannah RiverPlant, May 2, 1974. DP-1369, E.I. du Pont de Nemours \& Co., Savannah River Laboratory, Aiken, SC

2. Jacobsen, W. R.. 1975. Environmental Effects of a Tritium Gas Release From the Savannah River Plant on December 31, 1975. DP-1415, E. I. du Pont de Nemours \& Co., Inc., Savannah River Plant, Aiken,SC., USA

3. Garrett, A.J., E.L. Wilhite, and M. R. Buckner. 1981. Environmental Effects of a Tritium Release from the Savannah River Plant. DP1613. E. I. du Pont de Nemours \& Company, Inc., Savannah River Plant, Aiken, S. C., USA

4. Garrett, A. J., C. C. Zeigler, D. R. Carver, and D. A. Stevenson. 1983. Environmental Aspects of a Tritium Release from the Savannah River Plant on July 16, 1983. DP-1672, E.I. du Pont de Nemours \& Co., Savannah River Plant, Aiken, SC.

5.Evans, A.G.,D.D. Hoel, and M.V.Kantelo.1985. Environmental Aspects of a Tritium Release from the Savannah River Plant on March 23, 1984. DP-1695, E.I. du Pont de Nemours\& Co., Savannah River Laboratory, Aiken, SC

6. Hoel, D. D., R. J. Kurzeja, and A. G. Evans. Environmental Aspects of a Tritium Oxide Release from the Savannah River Site on September 2 and 3, 1984. WSRC-RP-90-814, Westinghouse Savannah River Company, Aiken, SC.

7. Zeigler, C., C. I. B. Lawrimore, E. M.. Heath. US Department of Energy Savannah River Plant Environmental Report for 1985 ,DPSPU 86-30-1, E.I. du Pont de Nemours and Co., Aiken, SC. 
8. Kurzeja, R.J., R.W. Taylor, J. Sharma, and L.T. Burckhalter. 1987. Environmental Effects of the July 31, 1987 Tritium Release from the Savannah River Plant. DP-1758, E.I. du Pont de Nemours \& Co., Inc., Savannah River Laboratory, Aiken,SC

9. Slade, D.H. 1968. Meteorology and Atomic Energy. USAEC, TID-24190, Clearinghouse for Federal Scientific and Technical Information, Springfield, VA. 

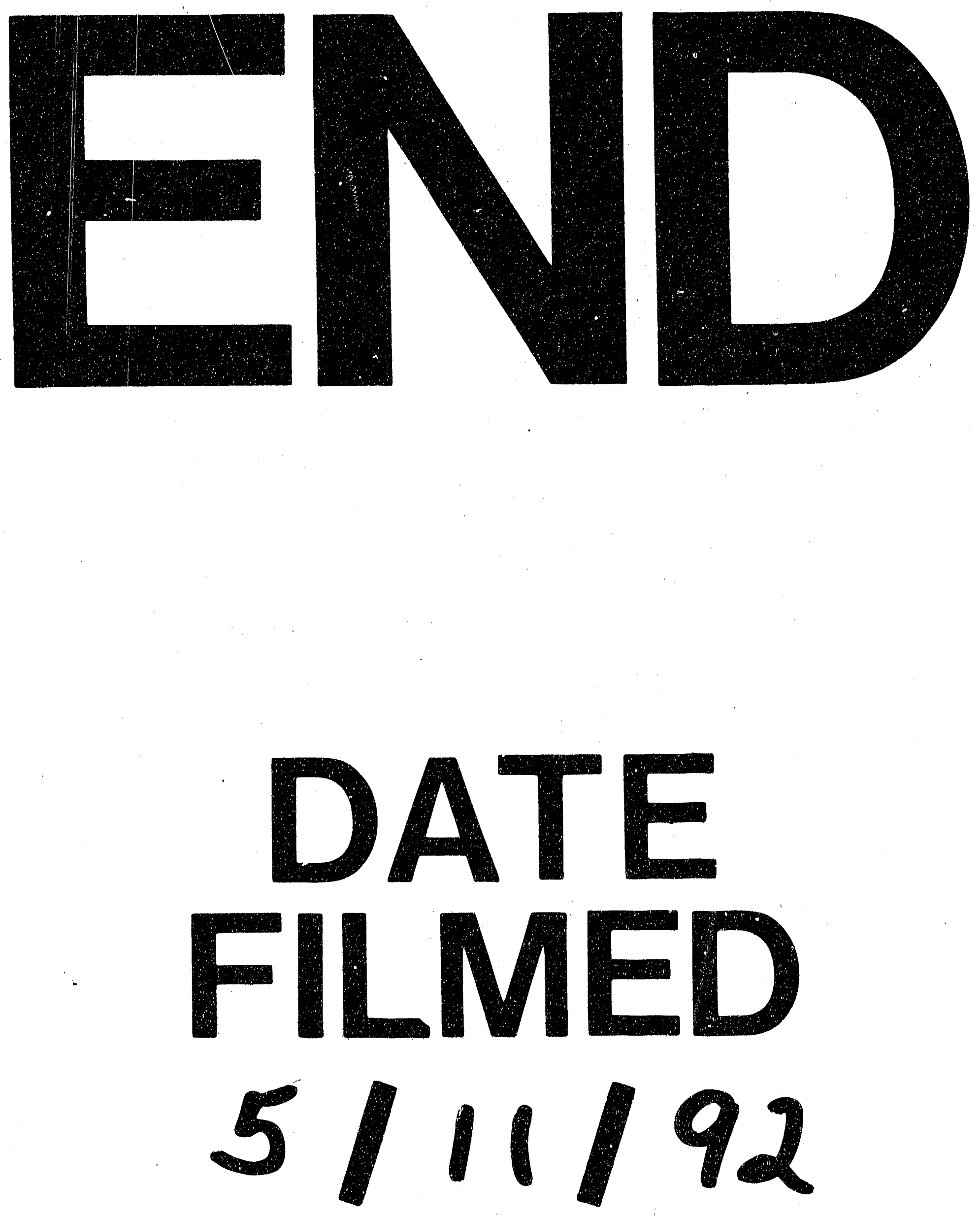
